\title{
Nonpharmaceutical Measures for Pandemic Influenza in Nonhealthcare Settings- Personal Protective and Environmental Measures
}

\author{
Jingyi Xiao, ${ }^{1}$ Eunice Y. C. Shiu, ${ }^{1}$ Huizhi Gao, Jessica Y. Wong, Min W. Fong, Sukhyun Ryu, Benjamin J. Cowling
}

There were 3 influenza pandemics in the 20th century, and there has been 1 so far in the 21st century. Local, national, and international health authorities regularly update their plans for mitigating the next influenza pandemic in light of the latest available evidence on the effectiveness of various control measures in reducing transmission. Here, we review the evidence base on the effectiveness of nonpharmaceutical personal protective measures and environmental hygiene measures in nonhealthcare settings and discuss their potential inclusion in pandemic plans. Although mechanistic studies support the potential effect of hand hygiene or face masks, evidence from 14 randomized controlled trials of these measures did not support a substantial effect on transmission of laboratory-confirmed influenza. We similarly found limited evidence on the effectiveness of improved hygiene and environmental cleaning. We identified several major knowledge gaps requiring further research, most fundamentally an improved characterization of the modes of person-to-person transmission.

nfluenza pandemics occur at irregular intervals
when new strains of influenza A virus spread in
humans (1). Influenza pandemics cause considerable
health and social impact that exceeds that of typical
seasonal (interpandemic) influenza epidemics. One
of the characteristics of influenza pandemics is the
high incidence of infections in all age groups because
of the lack of population immunity. Although influ-
enza vaccines are the cornerstone of seasonal influ-
enza control, specific vaccines for a novel pandemic
strain are not expected to be available for the first
$5-6$ months of the next pandemic. Antiviral drugs
will be available in some locations to treat more se-
vere infections but are unlikely to be available in the

Author affiliation: University of Hong Kong, Hong Kong, China

DOI: https://doi.org/10.3201/eid2605.190994 quantities that might be required to control transmission in the general community. Thus, efforts to control the next pandemic will rely largely on nonpharmaceutical interventions.

Most influenza virus infections cause mild and self-limiting disease; only a small fraction of casepatients require hospitalization. Therefore, influenza virus infections spread mainly in the community. Influenza virus is believed to be transmitted predominantly by respiratory droplets, but the size distribution of particles responsible for transmission remains unclear, and in particular, there is a lack of consensus on the role of fine particle aerosols in transmission $(2,3)$. In healthcare settings, droplet precautions are recommended in addition to standard precautions for healthcare personnel when interacting with influenza patients and for all visitors during influenza seasons (4). Outside healthcare settings, hand hygiene is recommended in most national pandemic plans (5), and medical face masks were a common sight during the influenza pandemic in 2009. Hand hygiene has been proven to prevent many infectious diseases and might be considered a major component in influenza pandemic plans, whether or not it has proven effectiveness against influenza virus transmission, specifically because of its potential to reduce other infections and thereby reduce pressure on healthcare services.

In this article, we review the evidence base for personal protective measures and environmental hygiene measures, and specifically the evidence for the effectiveness of these measures in reducing transmission of laboratory-confirmed influenza in the community. We also discuss the implications of the evidence base for inclusion of these measures in pandemic plans.

${ }^{1}$ These first authors contributed equally to this article. 


\section{Methods and Results}

We conducted systematic reviews to evaluate the effectiveness of personal protective measures on influenza virus transmission, including hand hygiene, respiratory etiquette, and face masks, and a systematic review of surface and object cleaning as an environmental measure (Table 1). We searched 4 databases (Medline, PubMed, EMBASE, and CENTRAL) for literature in all languages. We aimed to identify randomized controlled trials (RCTs) of each measure for laboratory-confirmed influenza outcomes for each of the measures because RCTs provide the highest quality of evidence. For respiratory etiquette and surface and object cleaning, because of a lack of RCTs for laboratory-confirmed influenza, we also searched for RCTs reporting effects of these interventions on influenza-like illness (ILI) and respiratory illness outcomes and then for observational studies on laboratory-confirmed influenza, ILI, and respiratory illness outcomes. For each review, 2 authors (E.Y.C.S. and J.X.) screened titles and abstracts and reviewed full texts independently.

We performed meta-analysis for hand hygiene and face mask interventions and estimated the effect of these measures on laboratory-confirmed influenza prevention by risk ratios (RRs). We used a fixed-effects model to estimate the overall effect in a pooled analysis or subgroup analysis. No overall effect would be generated if there was considerable heterogeneity on the basis of $I^{2}$ statistic $\geq 75 \%$ (6). We performed quality assessment of evidence on hand hygiene and face mask interventions by using the GRADE (Grading of Recommendations Assessment, Development and Evaluation) approach (7). We provide additional details of the search strategies, selection of articles, summaries of the selected articles, and quality assessment (Appendix, https://wwwnc.cdc. gov/EID/article/26/5/19-0994-App1.pdf).

\section{Personal Protective Measures}

\section{Hand Hygiene}

We identified a recent systematic review by Wong et al. on RCTs designed to assess the efficacy of hand hygiene interventions against transmission of laboratory-confirmed influenza (8). We used this review as a starting point and then searched for additional literature published after 2013; we found 3 additional eligible articles published during the search period of January 1, 2013-August 13, 2018. In total, we identified 12 articles (9-20), of which 3 articles were from the updated search and 9 articles from Wong et al. (8). Two articles relied on the same underlying dataset $(16,19)$; therefore, we counted these 2 articles as 1 study, which resulted in 11 RCTs. We further selected 10 studies with $>10,000$ participants for inclusion in the meta-analysis (Figure 1). We excluded 1 study from the meta-analysis because it provided estimates of infection risks only at the household level, not the individual level (20). We did not generate an overall pooled effect of hand hygiene only or of hand hygiene with or without face mask because of high heterogeneity in individual estimates $\left(I^{2} 87\right.$ and $82 \%$, respectively). The effect of hand hygiene combined with face masks on laboratory-confirmed influenza was not statistically significant (RR 0.91, 95\% CI $0.73-$ $\left.1.13 ; I^{2}=35 \%, p=0.39\right)$. Some studies reported being underpowered because of limited sample size, and low adherence to hand hygiene interventions was observed in some studies.

We further analyzed the effect of hand hygiene by setting because transmission routes might vary

\begin{tabular}{|c|c|c|c|}
\hline Types of interventions & No. studies identified & Study designs included $\dagger$ & Main findings \\
\hline Hand hygiene & 12 & $\mathrm{RCT}$ & $\begin{array}{l}\text { The evidence from RCTs suggested that } \\
\text { hand hygiene interventions do not have a } \\
\text { substantial effect on influenza transmission. }\end{array}$ \\
\hline Respiratory etiquette & 0 & NA & $\begin{array}{l}\text { We did not identify research evaluating the } \\
\text { effectiveness of respiratory etiquette on } \\
\text { influenza transmission. }\end{array}$ \\
\hline Face masks & 10 & RCT & $\begin{array}{l}\text { The evidence from RCTs suggested that the } \\
\text { use of face masks either by infected } \\
\text { persons or by uninfected persons does not } \\
\text { have a substantial effect on influenza } \\
\text { transmission. }\end{array}$ \\
\hline Surface and object cleaning & 3 & RCT, observational studies & $\begin{array}{c}\text { There was a limited amount of evidence } \\
\text { suggesting that surface and object cleaning } \\
\text { does not have a substantial effect on } \\
\text { influenza transmission. }\end{array}$ \\
\hline
\end{tabular}


A

Author (reference)

Hand hygiene

Events Total Events Total Weight Risk ratio $(95 \% \mathrm{Cl})$

Cowling et al. 2008 (12)

Cowling et al. 2009 (11)

Larson et al. 2010 (13)

Ram et al. 2015 (14)

Simmerman et al. 2011 (15) $66 \quad 292$

Stebbins et al. 2011 (16) 51 1,695

Talaat et al. $2011(18) \quad 125 \quad 808$

Heterogeneity: $I^{2}=87 \%, \tau^{2}=0.2837, p<0.01$

B

Author (reference)

Hand hygiene

Events Total

Aiello et al. 2010 (9) Aiello et al. 2012 (10) Cowling et al. 2009 (11) Larson et al. 2010 (13)

Simmerman et al. 2011

Suess et al. 2012 (17)

Fixed effect model

Test for overall effect: $z=-0.85(p=0.39)$

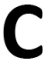

Author (reference)

Aiello et al. 2010 (9) Aiello et al. $2012(10)$

Cowling et al. 2008 (12)

Cowling et al. 2009 (11)

Larson et al. 2010 (13)

Ram et al. 2015 (14)

Stebbins et al. $2011(16) \quad 511,695$

Suess et al. $2012(17) \quad 10 \quad 67$

Talaat et al. $2011(18) \quad 125 \quad 808$

Heterogeneity: $I^{2}=82 \%, \mathrm{\tau}^{2}=0.2286, p<0.01$
Control

Events Total Weight Risk ratio $(95 \% \mathrm{Cl})$

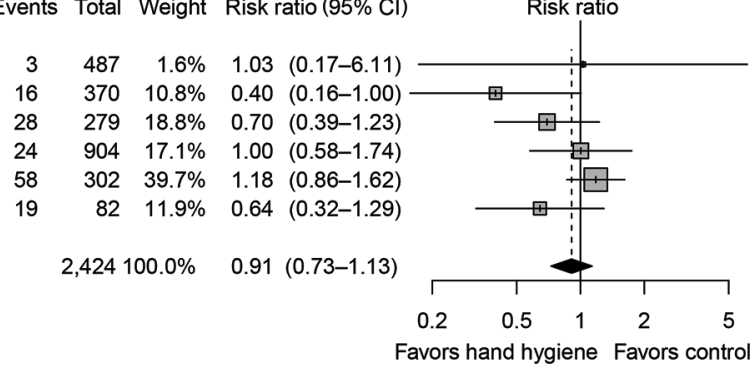

Figure 1. Meta-analysis of risk ratios for the effect of hand hygiene with or without face mask use on laboratory-confirmed influenza from 10 randomized controlled trials with $>11,000$ participants. A) Hand hygiene alone; B) hand hygiene and face mask; $C$ ) hand hygiene with or without face mask. Pooled estimates were not made if there was high heterogeneity $\left(R^{2} \geq 75 \%\right)$. Squares indicate risk ratio for each of the included studies, horizontal line indicates 95\% Cls, dashed vertical line indicates pooled estimation of risk ratio, and diamond indicates pooled estimation of risk ratio. Diamond width corresponds to the 95\% Cl. in different settings. We found 6 studies in household settings examining the effect of hand hygiene with or without face masks, but the overall pooled effect was not statistically significant (RR 1.05, 95\% CI $0.86-1.27 ; I^{2}=57 \%, p=0.65$ ) (Appendix Figure 4) $(11-15,17)$. The findings of 2 studies in school settings were different (Appendix Figure 5). A study conducted in the United States (16) showed no major effect of hand hygiene, whereas a study in Egypt (18) reported that hand hygiene reduced the risk for influenza by $>50 \%$. A pooled analysis of 2 studies in university residential halls reported a marginally significant protective effect of a combination of hand hygiene plus face masks worn by all residents (RR $0.48,95 \%$ CI $0.21-1.08 ; I^{2}=0 \%, p=0.08$ ) (Appendix Figure 6) $(9,10)$.

In support of hand hygiene as an effective measure, experimental studies have reported that influenza virus could survive on human hands for a short time and could transmit between hands and contaminated surfaces $(2,21)$. Some field studies reported that influenza $\mathrm{A}(\mathrm{H} 1 \mathrm{~N} 1) \mathrm{pdm} 09$ and influenza $\mathrm{A}(\mathrm{H} 3 \mathrm{~N} 2)$ virus RNA and viable influenza virus could be detected on the hands of persons with laboratory-confirmed influenza $(22,23)$, supporting the potential of direct and indirect contact transmission to play a role in the spread of influenza. Other experimental studies also demonstrated that hand hygiene could reduce or remove infectious influenza virus from human hands $(24,25)$. However, results from our meta-analysis on RCTs did not provide evidence to support a protective effect of hand hygiene against transmission of laboratory-confirmed influenza. One study did report a major effect, but in this trial of hand hygiene in schools in Egypt, running water had to be installed and soap and hand-drying 
material had to be introduced into the intervention schools as part of the project (18). Therefore, the impact of hand hygiene might also be a reflection of the introduction of soap and running water into primary schools in a lower-income setting. If one considers all of the evidence from RCTs together, it is useful to note that some studies might have underestimated the true effect of hand hygiene because of the complexity of implementing these intervention studies. For instance, the control group would not typically have zero knowledge or use of hand hygiene, and the intervention group might not adhere to optimal hand hygiene practices $(11,13,15)$.

Hand hygiene is also effective in preventing other infectious diseases, including diarrheal diseases and some respiratory diseases $(8,26)$. The need for hand hygiene in disease prevention is well recognized among most communities. Hand hygiene has been accepted as a personal protective measure in $>50 \%$ of national preparedness plans for pandemic influenza (5). Hand hygiene practice is commonly performed with soap and water, alcohol-based hand rub, or other waterless hand disinfectants, all of which are easily accessible, available, affordable, and well accepted in most communities. However, resource limitations in some areas are a concern when clean running water or alcohol-based hand rub are not available. There are few adverse effects of hand hygiene except for skin irritation caused by some hand hygiene products (27). However, because of certain social or religious practices, alcohol-based hand sanitizers might not be permitted in some locations (28). Compliance with proper hand hygiene practice tends to be low because habitual behaviors are difficult to change (29). Therefore, hand hygiene promotion programs are needed to advocate and encourage proper and effective hand hygiene.

\section{Respiratory Etiquette}

Respiratory etiquette is defined as covering the nose and mouth with a tissue or a mask (but not a hand) when coughing or sneezing, followed by proper disposal of used tissues, and proper hand hygiene after contact with respiratory secretions (30). Other descriptions of this measure have included turning the head and covering the mouth when coughing and coughing or sneezing into a sleeve or elbow, rather than a hand. The rationale for not coughing into hands is to prevent subsequent contamination of other surfaces or objects (31). We conducted a search on November 6, 2018, and identified literature that was available in the databases during 1946-November 5, 2018. We did not identify any published research on the effectiveness of respiratory etiquette in reducing the risk for laboratory-confirmed influenza or ILI. One observational study reported a similar incidence rate of self-reported respiratory illness (defined by $>1$ symptoms: cough, congestion, sore throat, sneezing, or breathing problems) among US pilgrims with or without practicing respiratory etiquette during the Hajj (32). The authors did not specify the type of respiratory etiquette used by participants in the study. A laboratory-based study reported that common respiratory etiquette, including covering the mouth by hands, tissue, or sleeve/arm, was fairly ineffective in blocking the release and dispersion of droplets into the surrounding environment on the basis of measurement of emitted droplets with a laser diffraction system (31).

Respiratory etiquette is often listed as a preventive measure for respiratory infections. However, there is a lack of scientific evidence to support this measure. Whether respiratory etiquette is an effective nonpharmaceutical intervention in preventing influenza virus transmission remains questionable, and worthy of further research.

\section{Face Masks}

In our systematic review, we identified 10 RCTs that reported estimates of the effectiveness of face masks in reducing laboratory-confirmed influenza virus infections in the community from literature published during 1946-July 27, 2018. In pooled analysis, we found no significant reduction in influenza transmission with the use of face masks (RR $0.78,95 \%$ CI $0.51-1.20 ; I^{2}=30 \%, \mathrm{p}=0.25$ ) (Figure 2 ). One study evaluated the use of masks among pilgrims from Australia during the Hajj pilgrimage and reported no major difference in the risk for laboratory-confirmed influenza virus infection in the control or mask group (33). Two studies in university settings assessed the effectiveness of face masks for primary protection by monitoring the incidence of laboratory-confirmed influenza among student hall residents for 5 months $(9,10)$. The overall reduction in ILI or laboratory-confirmed influenza cases in the face mask group was not significant in either studies $(9,10)$. Study designs in the 7 household studies were slightly different: 1 study provided face masks and P2 respirators for household contacts only (34), another study evaluated face mask use as a source control for infected persons only (35), and the remaining studies provided masks for the infected persons as well as their close contacts $(11-13,15,17)$. None of the household studies reported a significant reduction in secondary laboratory-confirmed influenza virus infections in the face 
A

$\begin{array}{lrr}\text { Author (reference) } & \begin{array}{c}\text { Mask } \\ \text { Events }\end{array} & \text { Total } \\ \text { Aiello et al. 2010 (19) } & 5 & 347 \\ \text { Aiello et al. 2012 (10) } & 12 & 392 \\ \text { Barasheed et al. 2014 (33) } & 1 & 11 \\ \text { Cowling et al. 2008 (12) } & 4 & 61 \\ \text { Maclntyre et al. 2009 (34) } & 1 & 94 \\ \text { Maclntyre et al. 2016 (35) } & 0 & 302 \\ \text { Suess et al. 2012 (17) } & 6 & 69 \\ & & 1,276 \\ \text { Fixed effect model } & & \\ \text { Heterogeneity: } I^{2}=30 \%, \tau^{2}=0.1899, p=0.20 \\ \text { Test for overall effect: } z=-1.15(p=0.25)\end{array}$

B Author (reference)

Aiello et al. 2010 (9) Aiello et al. 2012 (10) Cowling et al. 2009 (11) Larson et al. 2010 (13) Simmerman et al. $2011(1$
Suess et al. $2012(17)$ Suess et al. 2012 (17)

Fixed effect model $\quad 2,219$

Heterogeneity: $I^{2}=35 \%, \tau^{2}=0.0511, p=0.17$

Test for overall effect: $z=-0.85(p=0.39)$

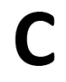

Author (reference)

Aiello et al. 2010 (9) Aiello et al. 2012 (10) Barasheed et al. 2014 (33) Cowling et al. 2009 (11) Cowling et al. 2008 (12)

Larson et al. 2010 (13)

Maclntyre et al. 2009 (34)

Macintyre et al. 2016 (35)

Simmerman et al. 2011 (15) $66 \quad 291$

Suess et al. $2012(17) \quad 16 \quad 136$

Fixed effect model

3,495

Heterogeneity: $I^{2}=30 \%, \tau^{2}=0.0593, p=0.17$

Test for overall effect: $z=-0.84(p=0.40)$
Control

Events Total Weight Risk ratio $(95 \% \mathrm{Cl})$

$\begin{array}{lllll}3 & 487 & 5.7 \% & 2.34 & (0.56-9.72)\end{array}$

$\begin{array}{lllll}16 & 370 & 37.3 \% & 0.71 & (0.34-1.48)\end{array}$

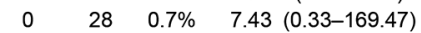

$12 \quad 205 \quad 12.5 \% \quad 1.12 \quad(0.37-3.35)$

$\begin{array}{lllll}0 & 100 & 1.1 \% & 3.19 & (0.13-77.36)\end{array}$

$\begin{array}{lllll}1 & 295 & 3.4 \% & 0.33 & (0.01-7.96)\end{array}$

$\begin{array}{lllll}19 & 82 & 39.4 \% & 0.38 & (0.16-0.89)\end{array}$

$1,567100.0 \% \quad 0.78 \quad(0.51-1.20)$

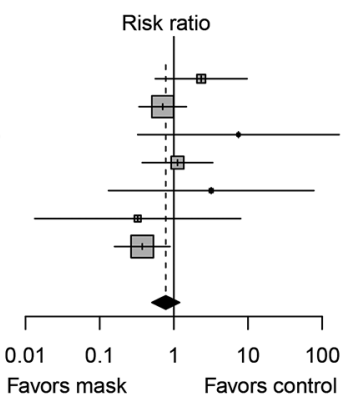

Control

Events Total Weight Risk ratio $(95 \% \mathrm{Cl})$

$487 \quad 1.6 \%$

$370 \quad 10.8 \%$

$27918.8 \%$

$90417.1 \%$

$30239.7 \%$

$8211.9 \%$

$2,424100.0 \%$

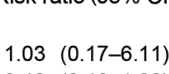

$0.40(0.16-1.00)$

$0.70(0.39-1.23)$

$1.00(0.58-1.74)$

$1.18(0.86-1.62)$

$0.64(0.32-1.29)$

$0.91(0.73-1.13)$

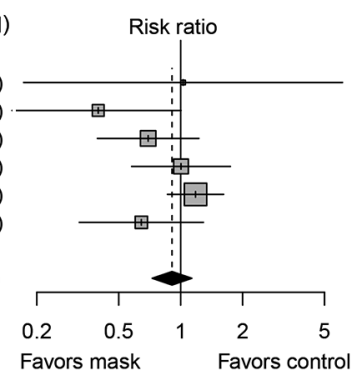

Control

Events Total Weight Risk ratio $(95 \% \mathrm{Cl})$

$\begin{array}{lll}3 & 487 & 2.1 \%\end{array}$

$\begin{array}{lll}16 & 370 & 13.0 \%\end{array}$

$28 \quad 0.2 \%$

$279 \quad 16.3 \%$

$2053.3 \%$

$90414.9 \%$

$100 \quad 0.3 \%$

$295 \quad 0.9 \%$

$302 \quad 34.6 \%$

$82 \quad 14.4 \%$

$3,052100.0 \%$
$.56 \quad(0.29-1.09)$

$7.43(0.33-169.47)$

$(0.39-1.23)$

$18 \quad(0.86-1.62)$

$0.92 \quad(0.75-1.12)$

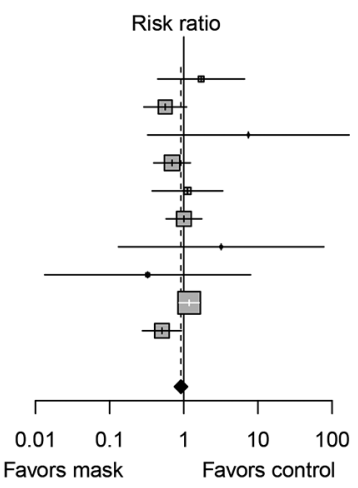

Figure 2. Meta-analysis of risk ratios for the effect of face mask use with or without enhanced hand hygiene on laboratory-confirmed influenza from 10 randomized controlled trials with $>6,500$ participants. A) Face mask use alone; B) face mask and hand hygiene; C) face mask with or without hand hygiene. Pooled estimates were not made if there was high heterogeneity $\left(I^{2} \geq 75 \%\right)$.

Squares indicate risk ratio for each of the included studies, horizontal lines indicate $95 \% \mathrm{Cls}$, dashed vertical lines indicate pooled estimation of risk ratio, and diamonds indicate pooled estimation of risk ratio. Diamond width corresponds to the $95 \% \mathrm{Cl}$. mask group (11-13,15,17,34,35). Most studies were underpowered because of limited sample size, and some studies also reported suboptimal adherence in the face mask group.

Disposable medical masks (also known as surgical masks) are loose-fitting devices that were designed to be worn by medical personnel to protect accidental contamination of patient wounds, and to protect the wearer against splashes or sprays of bodily fluids (36). There is limited evidence for their effectiveness in preventing influenza virus transmission either when worn by the infected person for source control or when worn by uninfected persons to reduce exposure. Our systematic review found no significant effect of face masks on transmission of laboratoryconfirmed influenza.
We did not consider the use of respirators in the community. Respirators are tight-fitting masks that can protect the wearer from fine particles (37) and should provide better protection against influenza virus exposures when properly worn because of higher filtration efficiency. However, respirators, such as N95 and P2 masks, work best when they are fit-tested, and these masks will be in limited supply during the next pandemic. These specialist devices should be reserved for use in healthcare settings or in special subpopulations such as immunocompromised persons in the community, first responders, and those performing other critical community functions, as supplies permit.

In lower-income settings, it is more likely that reusable cloth masks will be used rather than 
disposable medical masks because of cost and availability (38). There are still few uncertainties in the practice of face mask use, such as who should wear the mask and how long it should be used for. In theory, transmission should be reduced the most if both infected members and other contacts wear masks, but compliance in uninfected close contacts could be a problem $(12,34)$. Proper use of face masks is essential because improper use might increase the risk for transmission (39). Thus, education on the proper use and disposal of used face masks, including hand hygiene, is also needed.

\section{Environmental Measures}

\section{Surface and Object Cleaning}

For the search period from 1946 through October 14, 2018, we identified 2 RCTs and 1 observational study about surface and object cleaning measures for inclusion in our systematic review (40-42). One RCT conducted in day care nurseries found that biweekly cleaning and disinfection of toys and linen reduced the detection of multiple viruses, including adenovirus, rhinovirus, and respiratory syncytial virus in the environment, but this intervention was not significant in reducing detection of influenza virus, and it had no major protective effect on acute respiratory illness (41). Another RCT found that hand hygiene with hand sanitizer together with surface disinfection reduced absenteeism related to gastrointestinal illness in elementary schools, but there was no major reduction in absenteeism related to respiratory illness (42). A crosssectional study found that passive contact with bleach was associated with a major increase in selfreported influenza (40).

Given that influenza virus can survive on some surfaces for prolonged periods (43), and that cleaning or disinfection procedures can effectively reduce or inactivate influenza virus from surfaces and objects in experimental studies (44), there is a theoretical basis to believe that environmental cleaning could reduce influenza transmission. As an illustration of this proposal, a modeling study estimated that cleaning of extensively touched surfaces could reduce influenza $\mathrm{A}$ infection by $2 \%$ (45). However, most studies of influenza virus in the environment are based on detection of virus RNA by PCR, and few studies reported detection of viable virus.

Although we found no evidence that surface and object cleaning could reduce influenza transmission, this measure does have an established impact on prevention of other infectious diseases (42).
It should be feasible to implement this measure in most settings, subject to the availability of water and cleaning products. Although irritation caused by cleaning products is limited, safety remains a concern because some cleaning products can be toxic or cause allergies (40).

\section{Discussion}

In this review, we did not find evidence to support a protective effect of personal protective measures or environmental measures in reducing influenza transmission. Although these measures have mechanistic support based on our knowledge of how influenza is transmitted from person to person, randomized trials of hand hygiene and face masks have not demonstrated protection against laboratory-confirmed influenza, with 1 exception (18). We identified only 2 RCTs on environmental cleaning and no RCTs on cough etiquette.

Hand hygiene is a widely used intervention and has been shown to effectively reduce the transmission of gastrointestinal infections and respiratory infections (26). However, in our systematic review, updating the findings of Wong et al. (8), we did not find evidence of a major effect of hand hygiene on laboratory-confirmed influenza virus transmission (Figure 1). Nevertheless, hand hygiene might be included in influenza pandemic plans as part of general hygiene and infection prevention.

We did not find evidence that surgical-type face masks are effective in reducing laboratory-confirmed influenza transmission, either when worn by infected persons (source control) or by persons in the general community to reduce their susceptibility (Figure 2). However, as with hand hygiene, face masks might be able to reduce the transmission of other infections and therefore have value in an influenza pandemic when healthcare resources are stretched.

It is essential to note that the mechanisms of person-to-person transmission in the community have not been fully determined. Controversy remains over the role of transmission through fine-particle aerosols $(3,46)$. Transmission by indirect contact requires transfer of viable virus from respiratory mucosa onto hands and other surfaces, survival on those surfaces, and successful inoculation into the respiratory mucosa of another person. All of these components of the transmission route have not been studied extensively. The impact of environmental factors, such as temperature and humidity, on influenza transmission is also uncertain (47). These uncertainties over basic transmission modes and mechanisms hinder the optimization of control measures. 
Table 2. Knowledge gaps for personal protective and environmental nonpharmaceutical interventions for pandemic influenza*

Intervention Knowledge gaps $\quad$ Suggested studies

Hand hygiene There are major gaps in our knowledge of the mechanisms of person-to-person transmission of influenza, including the role of direct and indirect contact, the degree of viral contamination on hands and various types of surfaces in different settings, and the potential for contact transmission to occur in different locations and under different environmental conditions. There is little information on whether greater reductions in transmission could be possible with combinations of personal intervention (e.g., isolation away from family members as much as possible, plus using face masks and enhancing hand hygiene).

Respiratory etiquette There is no evidence about the quantitative effectiveness of respiratory etiquette against influenza virus.

Face mask There are major gaps in our knowledge of the mechanisms of person-to-person transmission of influenza, including the importance of transmission through droplets of different sizes including small particle aerosols, and the potential for droplet and aerosol transmission to occur in different locations and with environmental conditions.

\begin{tabular}{|c|c|}
\hline Surface and object cleaning & $\begin{array}{l}\text { The effectiveness of different cleaning products in } \\
\text { preventing influenza transmission-in terms of cleaning } \\
\text { frequency, cleaning dosage, cleaning time point, and } \\
\text { cleaning targeted surface and object material- } \\
\text { remains unknown }\end{array}$ \\
\hline
\end{tabular}
remains unknown.
Additional high-quality RCTs of efficacy of

hand hygiene against laboratory-confirmed

influenza in other nonhealthcare settings, except households and university residential halls, would be valuable. In particular, studies in school settings are needed to solve the discrepancy between the two studies from the United States and Egypt.

RCTs of interventions to demonstrate the effectiveness of respiratory etiquette in reducing influenza transmission would be valuable.

Additional high-quality RCTs of efficacy of face masks against laboratory-confirmed influenza would be valuable. Effectiveness of face masks or respirator use to prevent influenza prevention in special subpopulation, such as immunocompromised persons, would be valuable.

RCTs of interventions to demonstrate the effectiveness of surface and object

cleaning in reducing influenza transmission would be valuable. Studies that can demonstrate the reduction of environmental detection of influenza virus through cleaning of surfaces and objects would also be valuable.
In this review, we focused on 3 personal protective measures and 1 environmental measure. Other potential environmental measures include humidification in dry environments (48), increasing ventilation (49), and use of upper-room UV light (50), but there is limited evidence to support these measures. Further investigations on the effectiveness of respiratory etiquette and surface cleaning through conducting RCTs would be helpful to provide evidence with higher quality; evaluation of the effectiveness of these measures targeting specific population groups, such as immunocompromised persons, would also be beneficial (Table 2). Future cost-effectiveness evaluations could provide more support for the potential use of these measures. Further research on transmission modes and alternative interventions to reduce influenza transmission would be valuable in improving pandemic preparedness. Finally, although our review focused on nonpharmaceutical measures to be taken during influenza pandemics, the findings could also apply to severe seasonal influenza epidemics. Evidence from RCTs of hand hygiene or face masks did not support a substantial effect on transmission of laboratory-confirmed influenza, and limited evidence was available on other environmental measures.
This study was conducted in preparation for the development of guidelines by the World Health Organization on the use of nonpharmaceutical interventions for pandemic influenza in nonmedical settings.

This study was supported by the World Health Organization. J.X. and M.W.F. were supported by the Collaborative Research Fund from the University Grants Committee of Hong Kong (project no. C7025-16G).

\section{About the Author}

Ms. Xiao is a postgraduate student at the School of Public Health, University of Hong Kong, Hong Kong, China. Her primary research interests are influenza epidemiology and the dynamics of person-to-person transmission.

\section{References}

1. Uyeki TM, Katz JM, Jernigan DB. Novel influenza A viruses and pandemic threats. Lancet. 2017;389:2172-4. https:/ / doi.org/10.1016/S0140-6736(17)31274-6

2. Bean B, Moore BM, Sterner B, Peterson LR, Gerding DN, Balfour HH Jr. Survival of influenza viruses on environmental surfaces. J Infect Dis. 1982;146:47-51. https://doi.org/10.1093/infdis/146.1.47

3. Tellier R. Aerosol transmission of influenza A virus: a review of new studies. J R Soc Interface. 2009;6(Suppl 6):S783-90. https:/ / doi.org/10.1098/rsif.2009.0302.focus 
4. Siegel JD, Rhinehart E, Jackson M, Chiarello L; Health Care Infection Control Practices Advisory Committee. 2007 guideline for isolation precautions: preventing transmission of infectious agents in health care settings: Atlanta: Centers for Disease Control and Prevention; 2007.

5. World Health Organization. Comparative analysis of national pandemic influenza preparedness plans, 2011 [cited 2019 Jun 25]. https:/ / www.who.int/influenza/resources/ documents/comparative_analysis_php_2011_en.pdf

6. Guyatt GH, Oxman AD, Kunz R, Woodcock J, Brozek J, Helfand M, et al.; GRADE Working Group. GRADE guidelines: 7. Rating the quality of evidence-inconsistency. J Clin Epidemiol. 2011;64:1294-302. https:/ / doi.org/ 10.1016/j.jclinepi.2011.03.017

7. Guyatt G, Oxman AD, Akl EA, Kunz R, Vist G, Brozek J, et al. GRADE guidelines: 1. Introduction-GRADE evidence profiles and summary of findings tables. J Clin Epidemiol. 2011;64:383-94. https:// doi.org/10.1016/j.jclinepi. 2010.04.026

8. Wong VW, Cowling BJ, Aiello AE. Hand hygiene and risk of influenza virus infections in the community: a systematic review and meta-analysis. Epidemiol Infect. 2014;142:922-32. https://doi.org/10.1017/S095026881400003X

9. Aiello AE, Murray GF, Perez V, Coulborn RM, Davis BM, Uddin M, et al. Mask use, hand hygiene, and seasonal influenza-like illness among young adults: a randomized intervention trial. J Infect Dis. 2010;201:491-8. https:/ / doi.org/10.1086/650396

10. Aiello AE, Perez V, Coulborn RM, Davis BM, Uddin M, Monto AS. Facemasks, hand hygiene, and influenza among young adults: a randomized intervention trial. PLoS One. 2012;7:e29744. https://doi.org/10.1371/ journal.pone.0029744

11. Cowling BJ, Chan KH, Fang VJ, Cheng CK, Fung RO, Wai W, et al. Facemasks and hand hygiene to prevent influenza transmission in households: a cluster randomized trial. Ann Intern Med. 2009;151:437-46. https:/ / doi.org/10.7326/0003-4819-151-7-200910060-00142

12. Cowling BJ, Fung RO, Cheng CK, Fang VJ, Chan KH, Seto $\mathrm{WH}$, et al. Preliminary findings of a randomized trial of non-pharmaceutical interventions to prevent influenza transmission in households. PLoS One. 2008;3:e2101. https://doi.org/10.1371/journal.pone.0002101

13. Larson EL, Ferng YH, Wong-McLoughlin J, Wang S, Haber M, Morse SS. Impact of non-pharmaceutical interventions on URIs and influenza in crowded, urban households. Public Health Rep. 2010;125:178-91. https:/ / doi.org/10.1177/003335491012500206

14. Ram PK, DiVita MA, Khatun-e-Jannat K, Islam M, Krytus K, Cercone $\mathrm{E}$, et al. Impact of intensive handwashing promotion on secondary household influenza-like illness in rural bangladesh: findings from a randomized controlled trial. PLoS One. 2015;10:e0125200. https:/ / doi.org/10.1371/ journal.pone.0125200

15. Simmerman JM, Suntarattiwong P, Levy J, Jarman RG, Kaewchana S, Gibbons RV, et al. Findings from a household randomized controlled trial of hand washing and face masks to reduce influenza transmission in Bangkok, Thailand. Influenza Other Respir Viruses. 2011;5:256-67. https:/ / doi.org/10.1111/j.1750-2659.2011.00205.x

16. Stebbins S, Cummings DA, Stark JH, Vukotich C, Mitruka K, Thompson W, et al. Reduction in the incidence of influenza A but not influenza B associated with use of hand sanitizer and cough hygiene in schools: a randomized controlled trial. Pediatr Infect Dis J. 2011;30:921-6. https:/ / doi.org/10.1097/ INF.0b013e3182218656
17. Suess T, Remschmidt C, Schink SB, Schweiger B, Nitsche A, Schroeder $\mathrm{K}$, et al. The role of facemasks and hand hygiene in the prevention of influenza transmission in households: results from a cluster randomised trial; Berlin, Germany, 2009-2011. BMC Infect Dis. 2012;12:26. https:// doi.org/ 10.1186/1471-2334-12-26

18. Talaat M, Afifi S, Dueger E, El-Ashry N, Marfin A, Kandeel A, et al. Effects of hand hygiene campaigns on incidence of laboratory-confirmed influenza and absenteeism in schoolchildren, Cairo, Egypt. Emerg Infect Dis. 2011;17:619-25. https://doi.org/10.3201/eid1704.101353

19. Azman AS, Stark JH, Althouse BM, Vukotich CJ Jr, Stebbins S, Burke DS, et al. Household transmission of influenza A and B in a school-based study of nonpharmaceutical interventions. Epidemics. 2013;5:181-6. https://doi.org/10.1016/j.epidem.2013.09.001

20. Levy JW, Suntarattiwong P, Simmerman JM, Jarman RG, Johnson K, Olsen SJ, et al. Increased hand washing reduces influenza virus surface contamination in Bangkok households, 2009-2010. Influenza Other Respir Viruses. 2014;8:13-6. https://doi.org/10.1111/irv.12204

21. Mukherjee DV, Cohen B, Bovino ME, Desai S, Whittier S, Larson EL. Survival of influenza virus on hands and fomites in community and laboratory settings. Am J Infect Control. 2012;40:590-4. https:// doi.org/10.1016/j.ajic.2011.09.006

22. Macias AE, de la Torre A, Moreno-Espinosa S, Leal PE, Bourlon MT, Ruiz-Palacios GM. Controlling the novel A (H1N1) influenza virus: don't touch your face! J Hosp Infect. 2009;73:280-1. https://doi.org/10.1016/j.jhin.2009.06.017

23. Simmerman JM, Suntarattiwong P, Levy J, Gibbons RV, Cruz C, Shaman J, et al. Influenza virus contamination of common household surfaces during the 2009 influenza A (H1N1) pandemic in Bangkok, Thailand: implications for contact transmission. Clin Infect Dis. 2010;51:1053-61. https://doi.org/10.1086/656581

24. Grayson ML, Melvani S, Druce J, Barr IG, Ballard SA, Johnson PD, et al. Efficacy of soap and water and alcohol-based hand-rub preparations against live H1N1 influenza virus on the hands of human volunteers. Clin Infect Dis. 2009;48:285-91. https:/ / doi.org/10.1086/595845

25. Larson EL, Cohen B, Baxter KA. Analysis of alcohol-based hand sanitizer delivery systems: efficacy of foam, gel, and wipes against influenza A (H1N1) virus on hands. Am J Infect Control. 2012;40:806-9. https://doi.org/10.1016/ j.ajic.2011.10.016

26. Aiello AE, Coulborn RM, Perez V, Larson EL. Effect of hand hygiene on infectious disease risk in the community setting: a meta-analysis. Am J Public Health. 2008;98:1372-81. https:/ / doi.org/10.2105/AJPH.2007.124610

27. Löffler H, Kampf G. Hand disinfection: how irritant are alcohols? J Hosp Infect. 2008;70(Suppl 1):44-8. https:/ / doi.org/10.1016/S0195-6701(08)60010-9

28. Ahmed QA, Memish ZA, Allegranzi B, Pittet D; WHO Global Patient Safety Challenge. Muslim health-care workers and alcohol-based handrubs. Lancet. 2006;367: 1025-7. https:/ / doi.org/10.1016/S0140-6736(06)68431-6

29. Pittet D. Improving adherence to hand hygiene practice: a multidisciplinary approach. Emerg Infect Dis. 2001;7:234-40. https://doi.org/10.3201/eid0702.010217

30. Centers for Disease Control and Prevention. Respiratory hygiene/cough etiquette in healthcare settings, 2009 [cited 2019 Jul 8]. https:/ / www.cdc.gov/flu/professionals/ infectioncontrol/resphygiene.htm

31. Zayas G, Chiang MC, Wong E, MacDonald F, Lange CF, Senthilselvan A, et al. Effectiveness of cough etiquette maneuvers in disrupting the chain of transmission of 
infectious respiratory diseases. BMC Public Health. 2013;13:811. https:/ / doi.org/10.1186/1471-2458-13-811

32. Balaban V, Stauffer WM, Hammad A, Afgarshe M, Abd-Alla M, Ahmed Q, et al. Protective practices and respiratory illness among US travelers to the 2009 Hajj. J Travel Med. 2012;19:163-8. https:/ / doi.org/10.1111/ j.1708-8305.2012.00602.x

33. Barasheed $\mathrm{O}$, Almasri N, Badahdah AM, Heron L, Taylor J, McPhee K, et al.; Hajj Research Team. Pilot randomised controlled trial to test effectiveness of facemasks in preventing influenza-like illness transmission among Australian Hajj pilgrims in 2011. Infect Disord Drug Targets. 2014;14:110-6. https:/ / doi.org/10.2174/18715265146661410 21112855

34. MacIntyre CR, Cauchemez S, Dwyer DE, Seale H, Cheung P, Browne G, et al. Face mask use and control of respiratory virus transmission in households. Emerg Infect Dis. 2009;15:233-41. https:// doi.org/10.3201/eid1502.081166

35. MacIntyre CR, Zhang Y, Chughtai AA, Seale H, Zhang D, $\mathrm{Chu} Y$, et al. Cluster randomised controlled trial to examine medical mask use as source control for people with respiratory illness. BMJ Open. 2016;6:e012330. https:/ / doi.org/10.1136/bmjopen-2016-012330

36. US Food and Drug Administration. Masks and N95 respirators, 2018 [cited 2019 Jul 10]. https:/ / www.fda.gov/ medicaldevices/productsandmedicalprocedures/generalhospitaldevicesandsupplies/personalprotectiveequipment/ ucm055977.htm

37. Centers for Disease Control and Prevention. Respirator fact sheet, 2012 [cited 2019 Jul 10]. https:/ / www.cdc.gov/niosh/ npptl/topics/respirators/factsheets/respsars.html

38. Chughtai AA, Seale H, MacIntyre CR. Use of cloth masks in the practice of infection control-evidence and policy gaps. Int J Infect Control. 2013;9:1-12. https:/ / doi.org/10.3396/ IJIC.v9i3.020.13

39. World Health Organization. Advice on the use of masks in the community setting in Influenza A (H1N1) outbreaks, 2009 [cited 2019 Jul 10]. http:/ / www.who.int/csr/resources/ publications/Adviceusemaskscommunityrevised.pdf

40. Casas L, Espinosa A, Borràs-Santos A, Jacobs J, Krop E, Heederik D, et al. Domestic use of bleach and infections in children: a multicentre cross-sectional study. Occup Environ Med. 2015;72:602-4. https:/ / doi.org/10.1136/ oemed-2014-102701

41. Ibfelt T, Engelund EH, Schultz AC, Andersen LP. Effect of cleaning and disinfection of toys on infectious diseases and micro-organisms in daycare nurseries. J Hosp Infect. 2015;89:109-15. https://doi.org/10.1016/ j.jhin.2014.10.007
42. Sandora TJ, Shih MC, Goldmann DA. Reducing absenteeism from gastrointestinal and respiratory illness in elementary school students: a randomized, controlled trial of an infectioncontrol intervention. Pediatrics. 2008;121:e1555-62. https:// doi.org/10.1542/peds.2007-2597

43. Oxford J, Berezin EN, Courvalin P, Dwyer DE, Exner M, Jana LA, et al. The survival of influenza A(H1N1)pdm09 virus on 4 household surfaces. Am J Infect Control. 2014;42:423-5. https:/ / doi.org/10.1016/j.ajic.2013.10.016

44. Tuladhar E, Hazeleger WC, Koopmans M, Zwietering MH, Beumer RR, Duizer E. Residual viral and bacterial contamination of surfaces after cleaning and disinfection. Appl Environ Microbiol. 2012;78:7769-75. https:/ / doi.org/ 10.1128/AEM.02144-12

45. Zhang N, Li Y. Transmission of influenza A in a student office based on realistic person-to-person contact and surface touch behaviour. Int J Environ Res Public Health. 2018;15:E1699. https:// doi.org/10.3390/ijerph15081699

46. Shiu EY, Leung NHL, Cowling BJ. Controversy around airborne versus droplet transmission of respiratory viruses: implication for infection prevention. Curr Opin Infect Dis. 2019;32:372-9. https:/ / doi.org/10.1097/ QCO.0000000000000563

47. Marr LC, Tang JW, Van Mullekom J, Lakdawala SS. Mechanistic insights into the effect of humidity on airborne influenza virus survival, transmission and incidence. J R Soc Interface. 2019;16:20180298. https:/ / doi.org/10.1098/ rsif.2018.0298

48. Reiman JM, Das B, Sindberg GM, Urban MD, Hammerlund ME, Lee HB, et al. Humidity as a nonpharmaceutical intervention for influenza A. PLoS One. 2018; 13:e0204337. https://doi.org/10.1371/journal.pone.0204337

49. Gao X, Wei J, Cowling BJ, Li Y. Potential impact of a ventilation intervention for influenza in the context of a dense indoor contact network in Hong Kong. Sci Total Environ. 2016;569-570:373-81. https:/ / doi.org/10.1016/ j.scitotenv.2016.06.179

50. McDevitt JJ, Rudnick SN, Radonovich LJ. Aerosol susceptibility of influenza virus to UV-C light. Appl Environ Microbiol. 2012;78:1666-9. https:// doi.org/ 10.1128/ AEM.06960-11

Address for correspondence: Benjamin J. Cowling, World Health Organization Collaborating Centre for Infectious Disease Epidemiology and Control, School of Public Health, Li Ka Shing Faculty of Medicine, University of Hong Kong, 1/F Patrick Manson Bldg (North Wing), 7 Sassoon Rd, Hong Kong, China; email: bcowling@hku.hk 